\title{
Effect of oxide additives on the properties of high temperature superconductor, $\mathrm{YBa}_{2} \mathrm{Cu}_{3} \mathrm{O}_{7}$
}

\author{
K D CHANDRASEKARAN, U V VARADARAJU ${ }^{+}$, \\ A BARADARAJAN and G V SUBBA RAO ${ }^{+}$ \\ Department of Chemical Engineering, ${ }^{+}$Materials Science Research Centre, Indian \\ Institute of Technology, Madras 600036 , India \\ MS received 28 December 1988
}

\begin{abstract}
The effect of oxide additives $-\mathrm{CuO}, \mathrm{SiO}_{2}, \mathrm{Y}_{2} \mathrm{O}_{3}, \mathrm{Bi}_{2} \mathrm{O}_{3}$ and $\mathrm{ZnO}$ in $1-10 \mathrm{~mol} \%$ on the sintering and superconducting properties of $\mathrm{YBa}_{2} \mathrm{Cu}_{3} \mathrm{O}_{7}$ was studied. SEM studies indicated improvement of grain size and interconnectivity due to the additives, the best results being obtained with $\mathrm{Bi}_{2} \mathrm{O}_{3}, \mathrm{SiO}_{2}$ and $\mathrm{Y}_{2} \mathrm{O}_{3}$. The superconducting transition temperature is unaffected $(92 \pm 2 \mathrm{~K})$ even with $10 \mathrm{~mol} \%$ of the additives. $\mathrm{ZnO}$, however, decreases the $T_{c}$ as expected.
\end{abstract}

Keywords. High temperature superconductors; effect of additives; $\mathrm{YBa}_{2} \mathrm{Cu}_{3} \mathrm{O}_{7}$.

\section{Introduction}

The recent discovery of high temperature superconductivity in $\mathrm{YBa}_{2} \mathrm{Cu}_{3} \mathrm{O}_{7}$ with a $T_{\mathrm{c}}^{0}$ of $91 \mathrm{~K}$ by Wu et al (1987) and Cava et al (1987) and extensively investigated by many others (Chu et al 1987; Dhar et al 1987; Engler et al 1987; Ganguly et al 1987; Hikami et al 1987; Hosoya et al 1987; Matsushita et al 1987; Nagarajan et al 1987; Paulose et al 1987; Rao et al 1987; Rao and Ganguly 1987; Srinivasan et al 1987; Subba Rao et al 1987a, b; Takagi et al 1987) aroused worldwide interest for a detailed study and possible technological exploitation using liquid nitrogen (b.p. $77 \mathrm{~K}$ ) as the cryogen. $\mathrm{YBa}_{2} \mathrm{Cu}_{3} \mathrm{O}_{7}$ has outstanding superconducting properties (Dunlap et al 1987; Ellis 1987; Engler 1987; Xiao et al 1987; Narasimha Rao et al 1988; Rao 1988): a $T_{c}$ of $91 \mathrm{~K}$, well above the liquid $\mathrm{N}_{2}$ temperature; highest critical magnetic field $\left(H_{c 2}\right)$ known for any material $(>1500 \mathrm{kOe})$, short superconducting coherence length $(15-20 \AA)$ and $p$-type metallic behaviour. Oriented thin films of $\mathrm{YBa}_{2} \mathrm{Cu}_{3} \mathrm{O}_{7}$ have shown critical currents $\left(J_{c}\right)$ of $10^{6} \mathrm{~A} / \mathrm{cm}^{2}$ comparable to that of the low- $T_{\mathrm{c}}$ conventional superconductors like $\mathrm{Nb}_{3} \mathrm{Sn}$ and $\mathrm{Nb}-\mathrm{Ti}$ (Chaudhari et al 1987). However, studies on bulk and fabricated wires of $\mathrm{YBa}_{2} \mathrm{Cu}_{3} \mathrm{O}_{7}$ showed, till now, disappointingly low $J_{c}$ values: typically $150-500 \mathrm{~A} / \mathrm{cm}^{2}$ (Malik et al 1987; Sharma et al 1988) but in specially prepared wires, of the order of $7000 \mathrm{~A} / \mathrm{cm}^{2}$ (Jin et al 1987). This is attributed to the ceramic nature of the high $T_{c}$ oxide material and poor interconnectivity of the grains (Jarvinen et al 1988; Kilcoyne and Cyiwnski 1987). In essence, the grain structure and 'twinned' nature of $\mathrm{YBa}_{2} \mathrm{Cu}_{3} \mathrm{O}_{7}$ is responsible for the low $J_{c}$ encountered in bulk material. It is known that "pinning" centres incorporated into $\mathrm{YBa}_{2} \mathrm{Cu}_{3} \mathrm{O}_{7}$ can play a crucial role in increasing its $J_{c}$. These pinning centres can be foreign metal ions or impurities which however do not destroy the basic superconducting nature of $\mathrm{YBa}_{2} \mathrm{Cu}_{3} \mathrm{O}_{7}$. As a prelude to this, effect of oxide additives on $\mathrm{YBa}_{2} \mathrm{Cu}_{3} \mathrm{O}_{7}$ w.r.t. the $T_{c}$ behaviour, normal state resistivity, grain size and their interconnectivity need to be studied and optimized. 
Effect of chemical substitution on the superconductivity and related properties of $\mathrm{YBa}_{2} \mathrm{Cu}_{3} \mathrm{O}_{7}$ has been extensively studied in the literature (Dunlap et al 1987; Subba Rao et al 1987c; Varadaraju et al 1987; Xiao et al 1987; Narasimha Rao et al 1988; Rao 1988). Thus, while replacement of yttrium by other rare earth ions does not change the $T_{\mathrm{c}}$ of the compound, substitution at the Ba-site and particularly at she $\mathrm{Cu}$-site by either an ion of the same valency $(\mathrm{Sr}, \mathrm{Ca}$ or $\mathrm{Zn}, \mathrm{Ni}$ ) or aliovalent ions (e.g. $\mathrm{Fe}^{3+}, \mathrm{Al}^{3+}$ ) drastically decreases the $T_{c}$ of pure $\mathrm{YBa}_{2} \mathrm{Cu}_{3} \mathrm{O}_{7}$ and at sufficiently high concentrations, destroys the superconducting property completely. Kilcoyne and Cyiwnski (1987) studied the effect of partial substitution of yttrium by bismuth and barium by lead in $\mathrm{YBa}_{2} \mathrm{Cu}_{3} \mathrm{O}_{7}$ and found that while the $T_{c}$ remains unchanged, the normal state room temperature resistivity decreases by an order of magnitude. Both $\mathrm{Bi}$ and $\mathrm{Pb}$ oxides act as fluxes in the sintering process during the synthesis and changes in the morphology of the sintered grains were noted. However, there exists the possibility of the formation of impurity phases of the type, $\mathrm{BaBiO}_{3}$ and $\mathrm{BaPbO}_{3}$, along with the substituted $\mathrm{YBa}_{2} \mathrm{Cu}_{3} \mathrm{O}_{7}$.

On the other hand, studies on the effect of oxide additives on the $T_{c}$ behaviour of $\mathrm{YBa}_{2} \mathrm{Cu}_{3} \mathrm{O}_{7}$ are limited (Dou et al 1987; Jarvinen et al 1988). Jarvinen et al (1988) studied the effect of 22 oxide additives $(10 \mathrm{~mol} \%)$ on the $T_{c}$ and resistivity behaviour of $\mathrm{YBa}_{2} \mathrm{Cu}_{3} \mathrm{O}_{7}$. Significant findings are: (i) $\mathrm{ZrO}_{2}, \mathrm{~V}_{2} \mathrm{O}_{5}, \mathrm{WO}_{3}, \mathrm{In}_{2} \mathrm{O}_{3}$, $\mathrm{Bi}_{2} \mathrm{O}_{3}, \mathrm{SiO}_{2}, \mathrm{TiO}_{2}, \mathrm{BaO}, \mathrm{Nb}_{2} \mathrm{O}_{5}$ and $\mathrm{Sb}_{2} \mathrm{O}_{3}$ produced only a small but detectable change in the resistivity vs. temperature curves (including the transition temperature, $T_{c}$, of $90 \mathrm{~K}$ ), compared with the pure reference material. (ii) $\mathrm{Al}_{2} \mathrm{O}_{3}$, $\mathrm{MgO}$ and transition metal oxides such as $\mathrm{Cr}_{2} \mathrm{O}_{3}, \mathrm{Fe}_{2} \mathrm{O}_{3}, \mathrm{Co}_{2} \mathrm{O}_{3}, \mathrm{NiO}$ and $\mathrm{MoO}_{3}$ were found to strongly affect the $T_{c}$ as well as the width of the transition, $\Delta T_{c}$. (iii) Addition of silver oxide, $\mathrm{Ag}_{2} \mathrm{O}$, has the beneficial effect of increasing the steepness of the superconducting transition (and hence decrease of $\Delta T_{c}$ ). The beneficial effect of $\mathrm{Ag}$ or $\mathrm{Ag}_{2} \mathrm{O}$ addition has been noted by other workers (Malik et al 1988; Sharma et al 1988). (iv) In cases where the oxide additive has only a minor effect on $T_{c}$, the X-ray diffraction (XRD) patterns indicated the retention of the orthorhombic phase of the original reference material. In addition, the presence of impurity phases was detected for the additives $\mathrm{Nb}_{2} \mathrm{O}_{5}, \mathrm{Sb}_{2} \mathrm{O}_{3}, \mathrm{SnO}, \mathrm{WO}_{3}$ and $\mathrm{Bi}_{2} \mathrm{O}_{3}$. Intensity of select $(00 l)$ reflections of the orthorhombic phase of $\mathrm{YBa}_{2} \mathrm{Cu}_{3} \mathrm{O}_{7}$ were found to increase with the following additives: $\mathrm{Bi}_{2} \mathrm{O}_{3}, \operatorname{In}_{2} \mathrm{O}_{3}, \mathrm{Cr}_{2} \mathrm{O}_{3}$ and $\mathrm{V}_{2} \mathrm{O}_{5}$. This indicates that the grains of the superconducting material are 'oriented' preferentially. (v) Additives like $\mathrm{Fe}_{2} \mathrm{O}_{3}, \mathrm{Co}_{2} \mathrm{O}_{3}, \mathrm{Al}_{2} \mathrm{O}_{3}, \mathrm{MoO}_{3}$ which have a drastic effect on $T_{c}$ showed only the tetragonal phase of $\mathrm{YBa}_{2} \mathrm{Cu}_{3} \mathrm{O}_{7}$ and not the orthorhombic phase as can be expected.

In the present work, results of the studies on the effect of oxide additives $\mathrm{CuO}$, $\mathrm{ZnO}, \mathrm{Y}_{2} \mathrm{O}_{3}, \mathrm{Bi}_{2} \mathrm{O}_{3}$ and $\mathrm{SiO}_{2}$ in various proportions (ranging from $1-10 \mathrm{~mol} \%$ ) to $\mathrm{YBa}_{2} \mathrm{Cu}_{3} \mathrm{O}_{7}$ are reported. The oxides $\mathrm{ZnO}, \mathrm{Bi}_{2} \mathrm{O}_{3}$ and $\mathrm{SiO}_{2}$ are the usual wellknown sintering aids employed in the fabrication of oxide ceramics, which will improve the grain structure. $\mathrm{CuO}$ and $\mathrm{Y}_{2} \mathrm{O}_{3}$ are chosen in the present study because they form one of the components of the high $T_{c}$ ' 123 ' phase. Preliminary studies by other workers have shown that the stability and $T_{c}$ of $\mathrm{YBa}_{2} \mathrm{Cu}_{3} \mathrm{O}_{7}$ can be improved by $\mathrm{CuO}$ addition during processing (Subba Rao et al 1987b; Umarji and Nanjundaswamy 1987). 


\section{Experimental}

\subsection{Bulk synthesis of $\mathrm{YBa}_{2} \mathrm{Cu}_{3} \mathrm{O}_{7}$ and additive compositions}

Pure $\mathrm{YBa}_{2} \mathrm{Cu}_{3} \mathrm{O}_{7}$ in $250-300 \mathrm{~g}$ batches was synthesized by the high temperature solid state reaction of the constituent oxides and carbonates in stoichiometric proportions. The purity and source are: $\mathrm{Y}_{2} \mathrm{O}_{3}(99.99 \%$; Indian Rare Earths Ltd., Kerala); $\mathrm{BaCO}_{3}$ [99.5\%; Glaxo Laboratories (India) Ltd., Bombay]; CuO [99.9\%; prepared from copper metal rod/powder (99.9\%; Loba-Chemie IndoAustranal Co., Bombay) by dissolution in $\mathrm{AR} \mathrm{HNO}_{3}$ and decomposition of the nitrate above $800^{\circ} \mathrm{C}$ in air]. The starting materials were thoroughly mixed in a planetary agate ball mill (Fritsch, W. Germany) for one hour and the mixture calcined in air at $950^{\circ} \mathrm{C}$ for $24 \mathrm{~h}$ and cooled. The calcined powder was reground and pressed into lugs ( $4 \mathrm{~cm}$ dia; $1-2 \mathrm{~cm}$ thick containing about $50-75 \mathrm{~g}$ of material) and heated in air again for $24 \mathrm{~h}$ at $950^{\circ} \mathrm{C}$. The lugs, which were black in colour at this stage, were then crushed and ground to fine powder and used as the raw material for additive preparations. No oxygen treatment was carried out at this stage.

Ten gram batches of $\mathrm{YBa}_{2} \mathrm{Cu}_{3} \mathrm{O}_{7}$, along with the required amount of single additives, each corresponding to $1-10 \mathrm{~mol} \%$ of $\mathrm{CuO}(99.9 \%), \mathrm{Y}_{2} \mathrm{O}_{3}(99.99 \%), \mathrm{SiO}_{2}$ (99.9\% BDH, chromatographic grade), $\mathrm{Bi}_{2} \mathrm{O}_{3}(99.8 \%$; Alfa Ventron, USA) and $\mathrm{ZnO}$ $(99.0 \%$; Loba) were thoroughly mixed using an agate mortar and pestle, pressed into pellets $(8 \mathrm{~mm}$ or $12 \mathrm{~mm}$ dia; $1-2 \mathrm{~mm}$ thick using a WC-lined stainless steel die and plungers and pressure of $3-4 \mathrm{t}$ ) and heated at $930-950^{\circ} \mathrm{C}$ for $24 \mathrm{~h}$. The grinding, heating and cooling were repeated. The pellets were then oxygen-treated at $900^{\circ} \mathrm{C}$ in a tubular furnace for $24 \mathrm{~h}$ and subsequently at $600^{\circ} \mathrm{C}$ for an additional $24 \mathrm{~h}$ and then slowly cooled to room temperature by furnace shut-off maintaining the oxygen flow throughout the experiment.

\subsection{Characterization and physical studies}

The additive-containing phases along with the control sample (with no additive) were characterized by powder $\mathrm{X}$-ray diffraction (Philips unit; $\mathrm{Cu} \mathrm{K}_{\alpha}$-radiation, Ni-filter; $35 \mathrm{kV} ; 20 \mathrm{~mA}$ ) and bulk density. Superconducting behaviour was examined by the 'coil test' (previously calibrated with $\mathrm{YBa}_{2} \mathrm{Cu}_{3} \mathrm{O}_{7}$; details are described in Varadaraju et al 1989) and by the four-probe dc electrical resistivity as a function of temperature. The resistivity apparatus shown in figure 1 is a modified version originally used by Janaki (1985). The measurement is based on the van der Pauw's method modified by Montgomery (1971). Liquid $\mathrm{N}_{2}$ bath was used as the coolant to obtain temperatures in the range $80-300 \mathrm{~K}$. Ultrasonically impregnated indium metal contacts were used for soldering fine copper wire leads on pellets of $8 \mathrm{~mm}$ dia and 1-2 $\mathrm{mm}$ thickness. Temperatures were measured with a chromel-alumel thermocouple placed very near to the sample and are accurate to $\pm 1 \mathrm{~K}$. Voltage drop across the sample, through which a dc current of $15-50 \mathrm{~mA}$ was passed, was measured by a nanovoltmeter (Keithley, USA, model 181).

The superconducting transition onset temperature ( $T_{c}^{\text {onset }}$ ) was taken as the temperature at which there is significant departure from the linear variation of the high temperature region of the resistivity $(\rho)$ vs. temperature $(T)$ plot. $T_{c}^{0}$ is the temperature at and below which the $\rho=0$ as shown by zero voltage drop in the 


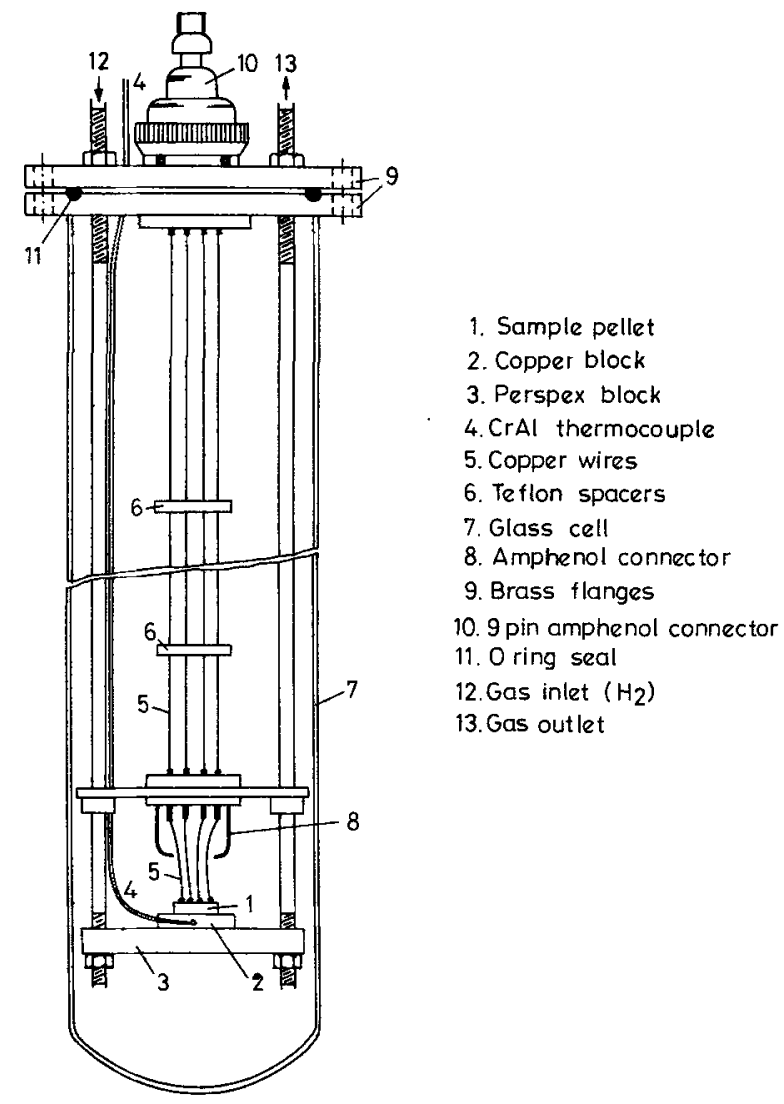

Figure 1. Schematic of four-probe d.c. electrical resistivity apparatus (range 80-300 K).

nanovoltmeter $(< \pm 10 \mathrm{nV}$ thermal noise; also, when the polarity of the current input to the sample is changed there will be no corresponding reversal of sign of voltage in nanovoltmeter reading) for varying amounts of current passed through the sample. $\Delta T_{c}$ is the width of the superconductivity transition, corresponding to the 90 and $10 \%$ drop in $\rho$ value.

Scanning electron microscope (SEM; Cambridge Stereoscan, UK, model 180) was employed to study the surface morphology of the compounds. Both polished and etched $(0.1 \mathrm{~N} \mathrm{HCl} ; 20 \mathrm{~s})$ samples were examined.

\section{Results and discussion}

\subsection{Stability and structure}

All the single additive compounds and control samples are black in colour and well-crystalline. The samples, in pellet form, are stable towards exposure to air and moisture and did not show degradation for at least 3-4 months, under ordinary conditions. However, they are usually stored in a desiccator to avoid exposure to high humidity conditions. The stability, crystallinity and phase purity of the 
presently synthesised samples is ascribed to the preparative conditions employed including oxygen treatment for prolonged periods of time. The bulk density of pellets of $\mathrm{YBa}_{2} \mathrm{Cu}_{3} \mathrm{O}_{7}$ alone and with the oxide additives ranges from $5 \cdot 0-5 \cdot 6 \mathrm{~g} / \mathrm{cc}$ corresponding to $70-75 \%$ theoretical $\mathrm{X}$-ray density. Oxygen estimation was not done specifically for the additive-containing $\mathrm{YBa}_{2} \mathrm{Cu}_{3} \mathrm{O}_{7}$, but from previous experiments on control samples, prepared under identical conditions, the $\delta$ in $\mathrm{YBa}_{2} \mathrm{Cu}_{3} \mathrm{O}_{7-\delta}$ was in the range $0 \cdot 10 \pm 0.05$, and this corresponds to welloxygenated samples. This is also corroborated by the powder X-ray diffraction (XRD) and superconductivity data.

XRD data on the control sample and all the additive-containing samples indicated orthorhombic perovskite structure corresponding to the ' 123 ' phase. The values of lattice parameters obtained for the control sample (viz. $a=3.82 ; b=3.88$; $c=11.67 \AA$ ) are in excellent agreement with those reported in the literature. In addition to the lines due to the ' 123 " phase, lines due to impurity phases were seen in the following additive-containing $\mathrm{YBa}_{2} \mathrm{Cu}_{3} \mathrm{O}_{7}$ : (i) $\mathrm{CuO}$ peaks for the $\mathrm{CuO}$ additive; composition, $>2 \mathrm{~mol} \%$ (figure $2 \mathrm{a}$ ); (ii) $\mathrm{Y}_{2} \mathrm{BaCuO}_{5}$ peaks for the $\mathrm{Y}_{2} \mathrm{O}_{3}$. additive; composition $>3$ mol\%; (iii) $\mathrm{BaBiO}_{3}$ peaks for $\mathrm{Bi}_{2} \mathrm{O}_{3}$-additive; composition $>4 \mathrm{~mol} \%$ (figure 2b). No lines due to $\mathrm{SiO}_{2}$ or $\mathrm{ZnO}$ or $\mathrm{BaSiO}_{3}$ or $\mathrm{BaZnO}_{2}$ were seen for $\mathrm{SiO}_{2}$ and $\mathrm{ZnO}$ additive samples. These observations indicate that: (i) The solid solubility of $\mathrm{CuO}$ and $\mathrm{Y}_{2} \mathrm{O}_{3}$ in $\mathrm{YBa}_{2} \mathrm{Cu}_{3} \mathrm{O}_{7}$ is very small; (ii) $\mathrm{BaBiO}_{3}$, which is a perovskite (Sleight et al 1975), formation is energetically more favourable under the high temperature conditions and can extract $\mathrm{Ba}$ from $\mathrm{YBa}_{2} \mathrm{Cu}_{3} \mathrm{O}_{7}$ (leaving $\mathrm{Y}_{2} \mathrm{BaCuO}_{5}$ or $\mathrm{CuO}$ impurities in addition to the '123' phase) and thus solid solubility of $\mathrm{Bi}$ in ' 123 ' is small; (iii) $\mathrm{SiO}_{2}$ may form a glassy phase which is amorphous to XRD but no solid solubility of Si occurs to form a phase of the form, $\mathrm{YBa}_{2} \mathrm{Cu}_{3-x} \mathrm{Si}_{x} \mathrm{O}_{7}$; (iv) on the other hand, $\mathrm{Zn}$ can be doped into ' $123^{\prime}$ partly

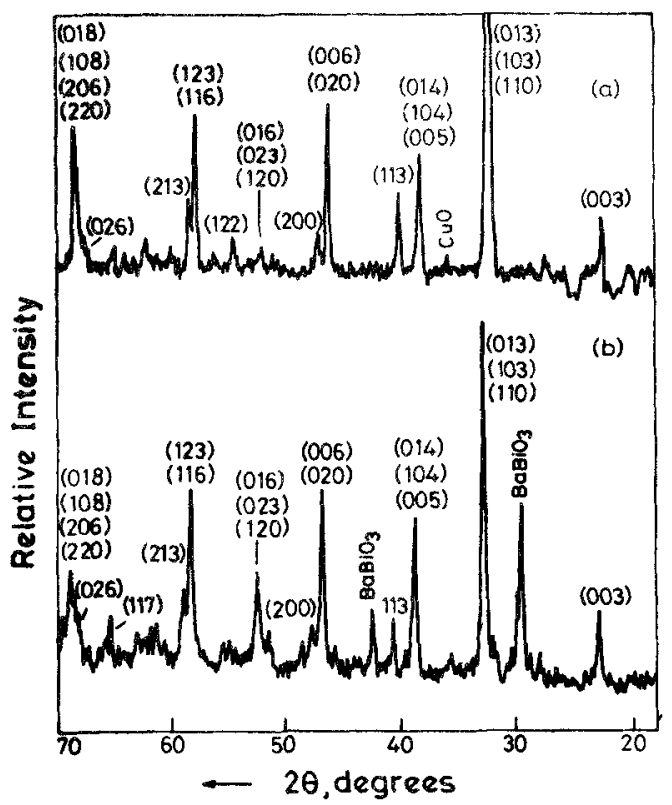

Figure 2. XRD patterns of ' 123 ' with (a) $\mathrm{CuO} 5 \mathrm{~mol} \%$ and (b) $\mathrm{Bi}_{2} \mathrm{O}_{3}-4 \mathrm{~mol} \%$. 


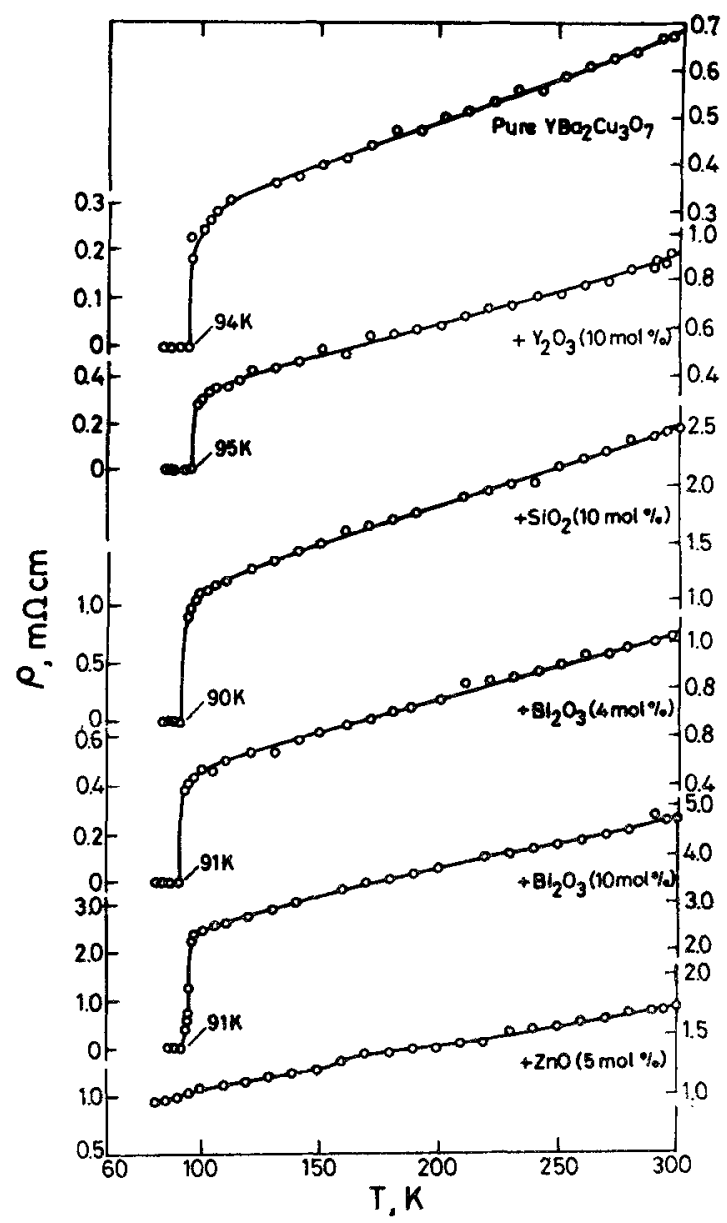

Figure 3. Resistivity versus temperature plots of pure and additive $\left(\mathrm{Y}_{2} \mathrm{O}_{3}, \mathrm{SiO}_{2}, \mathrm{Bi}_{2} \mathrm{O}_{3}\right.$ and $\mathrm{ZnO}$ )-containing $\mathrm{YBa}_{2} \mathrm{Cu}_{3} \mathrm{O}_{7}$, showing superconductivity transitions ( $\mathrm{ZnO}$ exception).

Table 1. Resistivity and superconductivity data on pure and oxide-additive $\mathrm{YBa}_{2} \mathrm{Cu}_{3} \mathrm{O}_{7}$ phases.

\begin{tabular}{|c|c|c|c|c|c|c|c|}
\hline $\begin{array}{l}\text { Additives } \\
\text { (mol\%) }\end{array}$ & & $\begin{array}{c}T_{c} \text { onset } \\
(\mathbf{K})\end{array}$ & $\begin{array}{c}T_{c}^{0} \\
(\mathrm{~K})\end{array}$ & $\begin{array}{l}\Delta T_{\mathrm{c}} \\
(\mathrm{K})\end{array}$ & $\begin{array}{c}\rho_{300 \mathrm{~K}} \\
(\mathrm{~m} \Omega \mathrm{cm})\end{array}$ & $\begin{array}{l}\rho_{\mathrm{t} 10 \mathrm{~K}} \\
\mathrm{~m} \Omega \mathrm{cm}\end{array}$ & $\begin{array}{c}\left(1 / \rho_{300 \mathrm{~K}}\right)(\mathrm{d} \rho / \mathrm{d} T) \\
\text { (range } \\
140-240 \mathrm{~K})\end{array}$ \\
\hline \multirow{3}{*}{$\begin{array}{l}\text { Pure } \\
\mathrm{Y}_{2} \mathrm{O}_{3}\end{array}$} & $\mathrm{YBa}_{2} \mathrm{Cu}_{3} \mathrm{O}_{7}$ & 105 & 94 & 3 & 0.69 & $0 \cdot 21$ & 2.9 \\
\hline & (5) & 110 & 94 & 5 & $1 \cdot 23$ & 0.63 & $2 \cdot 6$ \\
\hline & (10) & 105 & 95 & 4 & 0.90 & $0 \cdot 36$ & $3 \cdot 11$ \\
\hline \multirow[t]{2}{*}{$\mathrm{SiO}_{2}$} & (5) & 110 & 94 & $7 \cdot 5$ & $1 \cdot 28$ & 0.61 & $2 \cdot 66$ \\
\hline & (10) & 115 & 90 & 12 & $2 \cdot 50$ & 1.22 & $2 \cdot 52$ \\
\hline \multirow[t]{2}{*}{$\mathrm{Bi}_{2} \mathrm{O}_{3}$} & (4) & 96 & 90 & 2 & 1.03 & $0 \cdot 50$ & $2 \cdot 72$ \\
\hline & (10) & 100 & 91 & 3 & 480 & $2 \cdot 60$ & $2 \cdot 4$ \\
\hline $\mathrm{CuO}$ & (5) & 100 & 92 & 2 & 0.74 & $0 \cdot 30$ & $3 \cdot 11$ \\
\hline $\mathrm{ZnO}$ & (5) & -- & - & - & $1 \cdot 73$ & $1 \cdot 10$ & 1.97 \\
\hline
\end{tabular}



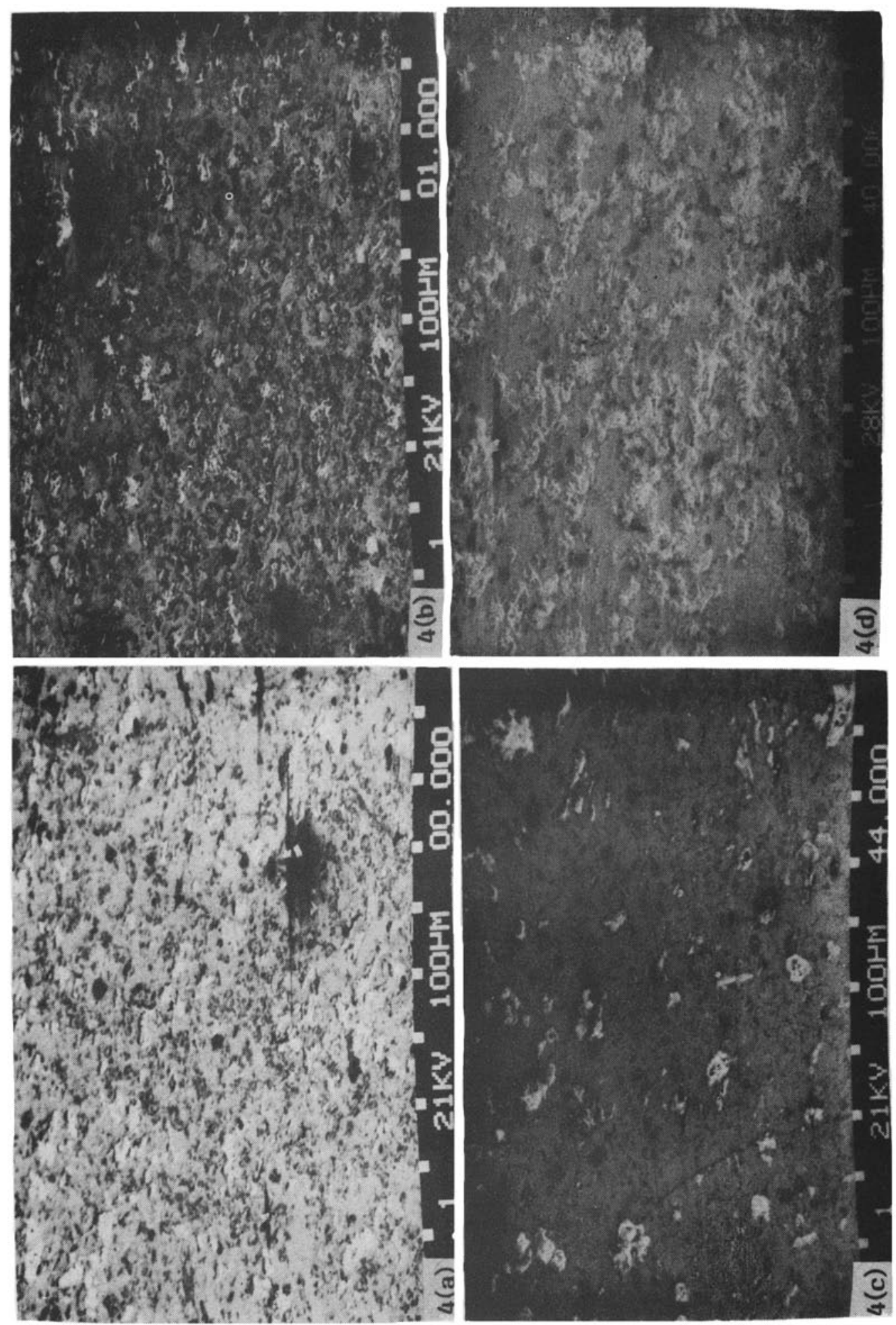

Figures 4a-d. For caption, see p. 91. 

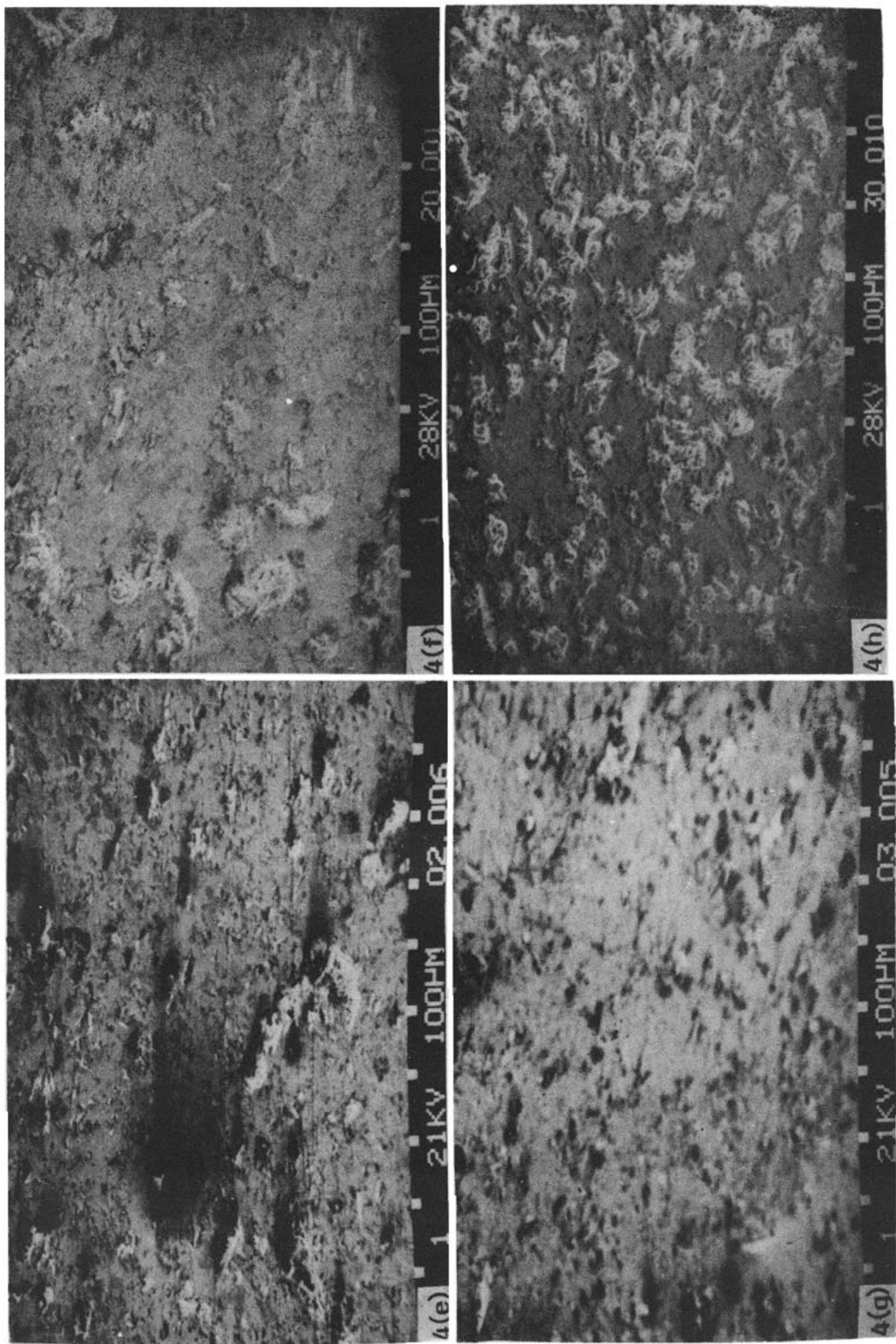

Figures $4 \mathbf{e}-\mathbf{h}$. For caption, see p. 91. 

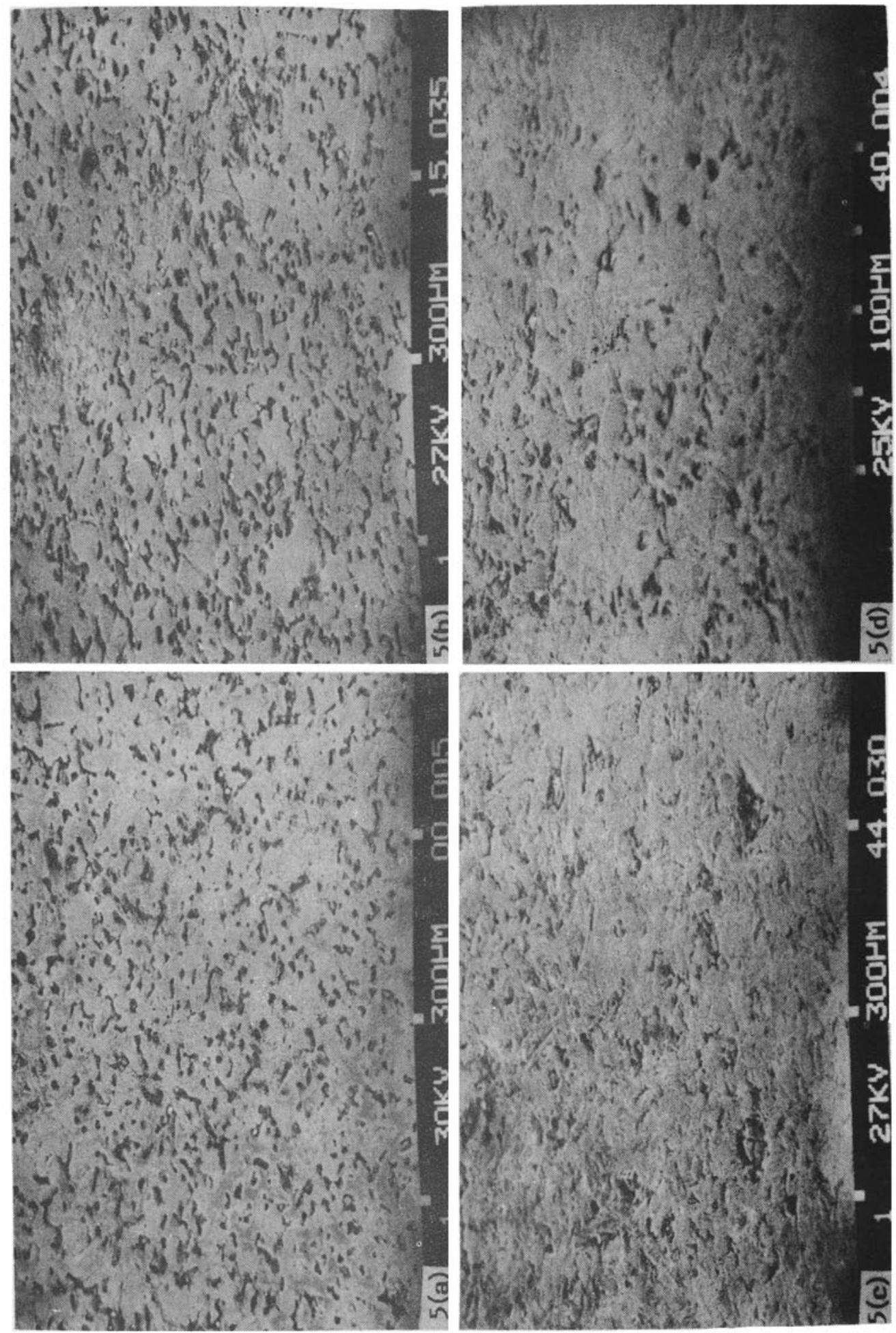

Figures 5a-d. For caption, see p. 91. 

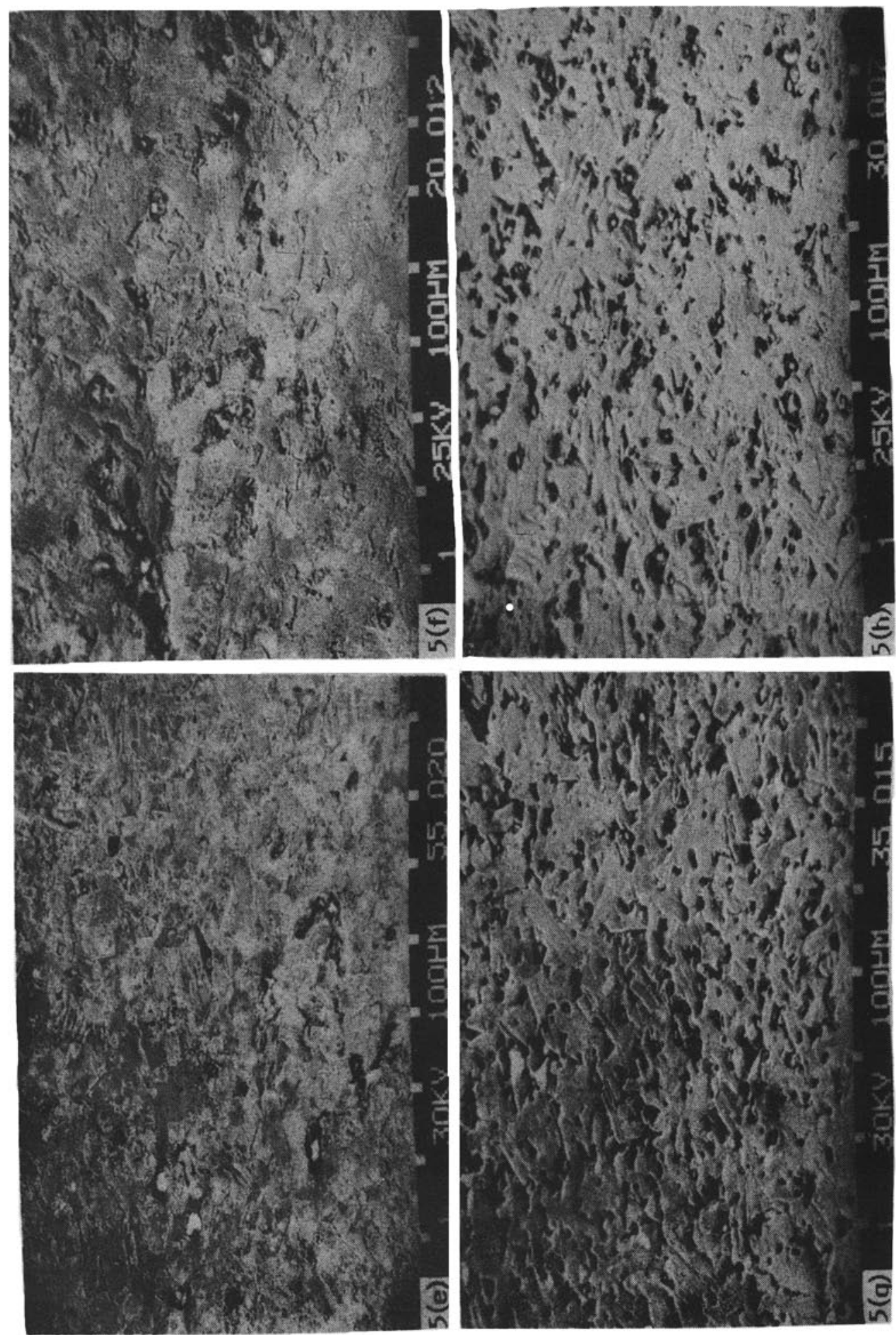

Figures 5e-f. For caption, see p. 91 . 
replacing copper and thereby produce changes in the physical properties. The latter finding is consistent with the observations by others in the literature (Dunlap et al 1987; Xiao et al 1987; Krishnan et al 1988; Narasimha Rao et al 1988). However, there are no significant changes in the lattice parameters of the parent $\mathrm{YBa}_{2} \mathrm{Cu}_{3} \mathrm{O}_{7}$ in all the above cases. Though Jarvinen et al (1988) did not specifically mention the formation of a $\mathrm{BaBiO}_{3}$ phase in their experiments on the $\mathrm{Bi}_{2} \mathrm{O}_{3}$ additive to $\mathrm{YBa}_{2} \mathrm{Cu}_{3} \mathrm{O}_{7}$, since it is stated that the solid solubility is small with $\mathrm{Bi}_{2} \mathrm{O}_{3}$, it can be safely presumed that $\mathrm{BaBiO}_{3}$ existed as an impurity in their phases.

The coil (quick) test for superconductivity has been performed on all the additive containing compounds in addition to the control (pure) $\mathrm{YBa}_{2} \mathrm{Cu}_{3} \mathrm{O}_{7}$. Since the samples (and the coils) are dipped in liquid $\mathrm{N}_{2}$, no temperature variation is possible but the test indicates whether the compounds are superconducting or not at and above $77 \mathrm{~K}$. Tests have shown that with the exception of $\mathrm{ZnO}$-containing phase, all the other additive compounds including the control $\mathrm{YBa}_{2} \mathrm{Cu}_{3} \mathrm{O}_{7}$ are superconducting at and above $77 \mathrm{~K}$. This reiterates the statement made earlier that the solid solubility of the additives $\mathrm{CuO}, \mathrm{Y}_{2} \mathrm{O}_{3}, \mathrm{Bi}_{2} \mathrm{O}_{3}$ and $\mathrm{SiO}_{2}$ in the parent $\mathrm{YBa}_{2} \mathrm{Cu}_{3} \mathrm{O}_{7}$ is small and that the basic features of $\mathrm{YBa}_{2} \mathrm{Cu}_{3} \mathrm{O}_{7}$ are retained. However, it was noted that for the same quantity of the samples tested $(\sim 100-200 \mathrm{mg})$ by the coil test, the superconductivity signal strength was relatively small in $10 \mathrm{~mol} \% \mathrm{Bi}_{2} \mathrm{O}_{3}$ and $\mathrm{SiO}_{2}$ containing samples, as compared to the control sample of $\mathrm{YBa}_{2} \mathrm{Cu}_{3} \mathrm{O}_{7}$. The fact that the $5 \mathrm{~mol} \% \mathrm{ZnO}$ containing $\mathrm{YBa}_{2} \mathrm{Cu}_{3} \mathrm{O}_{7}$ is not superconducting at $77 \mathrm{~K}$ indicates that either $T_{c}$ is below $77 \mathrm{~K}$ or is destroyed completely. Earlier studies have shown that when $\mathrm{Cu}$ is substituted by $5 \mathrm{~mol} \% \mathrm{Zn}$, the $T_{c}$ is lowered below $60 \mathrm{~K}$ (Dunlap et al 1987; Xiao et al 1987; Krishnan et al 1989; Narasimha Rao et al 1988).

To check on the stability of the $\mathrm{YBa}_{2} \mathrm{Cu}_{3} \mathrm{O}_{7}$ and additive containing phases, the coil test was carried out, on samples that have been stored without any precautions, after a month. The superconducting signal strength was unchanged in the control and $\mathrm{Y}_{2} \mathrm{O}_{3}$-containing (in the range $\left.1-10 \%\right) \mathrm{YBa}_{2} \mathrm{Cu}_{3} \mathrm{O}_{7}$, while there was only marginal decrease (by about 5-10\%) in the $\mathrm{CuO}-, \mathrm{Bi}_{2} \mathrm{O}_{3^{-}}$and $\mathrm{SiO}_{2}$-containing material.

Four-probe d.c. electrical resistivity $(\rho)$ data of pure and additive-containing $\mathrm{YBa}_{2} \mathrm{Cu}_{3} \mathrm{O}_{7}$ in the range $85-300 \mathrm{~K}$ indicated metallic behaviour with $\rho_{300 \mathrm{~K}}$ in the range $0 \cdot 3-2 \cdot 0$ milliohm $\mathrm{cm}$. The $\rho-\mathrm{T}$ data in the range $140-300 \mathrm{~K}$ can be fitted into an equation of the form $\rho=A+B T$ where $A$ and $B$ are constants. Transition to a superconducting state was observed in all the phases except where $\mathrm{ZnO}$ was the additive. The latter phase remained metallic in the range $83-300 \mathrm{~K}$ (figure 3 and table 1). The $T_{c}^{0}$ values are in the range $92 \pm 2$ in all the compounds indicating

Figure 4. Surface morphology by SEM of polished specimens of $\mathrm{YBa}_{2} \mathrm{Cu}_{3} \mathrm{O}_{7}$ and with additives $(100 \times)$. (a) Pure $\mathrm{YBa}_{2} \mathrm{Cu}_{3} \mathrm{O}_{7}$; (b) $\mathrm{CuO}-5 \mathrm{~mol} \%$; (c) $\mathrm{Bi}_{2} \mathrm{O}_{3}-4 \mathrm{~mol} \%$; (d) $\mathrm{Bi}_{2} \mathrm{O}_{3}-10 \mathrm{~mol} \%$; (e) $\mathrm{SiO}_{2}-5 \mathrm{~mol} \%$; (f) $\mathrm{SiO}_{2}-10 \mathrm{~mol} \%$; (g) $\mathrm{Y}_{2} \mathrm{O}_{3}-5 \mathrm{~mol} \%$; (h) $\mathrm{Y}_{2} \mathrm{O}_{3}-$ $10 \mathrm{~mol} \%$.

Figure 5. Surface morphology by SEM of polished and etched $(0.1 \mathrm{~N} \mathrm{HCl}$ for $20 \mathrm{~s})$ specimens of $\mathrm{YBa}_{2} \mathrm{Cu}_{3} \mathrm{O}_{7}$ and with additives $\left(100 \times\right.$ ). (a) $\mathrm{Pure}_{\mathrm{YBa}} \mathrm{Cu}_{3} \mathrm{O}_{7} ;$ (b) $\mathrm{CuO}-5 \mathrm{~mol} \%$; (c) $\mathrm{Bi}_{2} \mathrm{O}_{3}-4 \mathrm{~mol} \%$; $\quad$ (d) $\mathrm{Bi}_{2} \mathrm{O}_{3}-10 \mathrm{~mol} \%$; $\quad$ (e) $\mathrm{ZnO}-5 \mathrm{~mol} \%$; (f) $\mathrm{SiO}_{2}-10 \mathrm{~mol} \%$; (g) $\mathrm{Y}_{2} \mathrm{O}_{3}-5 \mathrm{~mol} \%$; (h) $\mathrm{Y}_{2} \mathrm{O}_{3}-10 \mathrm{~mol} \%$. 
negligible effect of the oxide additives on the inherent superconducting behaviour of $\mathrm{YBa}_{2} \mathrm{Cu}_{3} \mathrm{O}_{7}$. It is of specific interest to note that $10 \% \mathrm{SiO}_{2}$ addition does not affect the $T_{c}$. It is worthwile studying higher concentrations of $\mathrm{SiO}_{2}$ to see whether a glass-ceramic composition can be obtained which still retains the high $T_{c}$ behaviour.

SEM studies on pure and additive-containing $\mathrm{YBa}_{2} \mathrm{Cu}_{3} \mathrm{O}_{7}$ have been made on polished, and polished and etched samples. Etching by $0.1 \mathrm{~N} \mathrm{HCl}$ gave rise to a white layer (not easily seen with the naked eye but visible on SEM) indicating, perhaps, the formation of a $\mathrm{Y}_{2} \mathrm{O}_{3}$ layer. However, as can be seen in figures 4 and 5 , the surface morphology can easily be discerned. $\mathrm{Bi}_{2} \mathrm{O}_{3}$ and $\mathrm{SiO}_{2}$ additives improve the grain size and their interconnectivity compared to the ones containing $\mathrm{CuO}$ or $\mathrm{Y}_{2} \mathrm{O}_{3}$. Increasing the $\mathrm{Bi}_{2} \mathrm{O}_{3}$ content has a beneficial effect but as is known from $\mathrm{XRD}$, higher concentrations yield an increasing second phase $\left(\mathrm{BaBiO}_{3}\right)$. Perhaps, it is worthwhile studying the effect of $\mathrm{BaBiO}_{3}$ addition to $\mathrm{YBa}_{2} \mathrm{Cu}_{3} \mathrm{O}_{7}$.

\section{Summary and conclusions}

Effect of five oxide additives on the superconductivity behaviour of $\mathrm{YBa}_{2} \mathrm{Cu}_{3} \mathrm{O}_{7}$ has been studied. Except for $\mathrm{ZnO}$ which produces a decrease in $T_{c}$ (to below $77 \mathrm{~K}$ ), the oxides $\mathrm{CuO}, \mathrm{Y}_{2} \mathrm{O}_{3}, \mathrm{Bi}_{2} \mathrm{O}_{3}$ and $\mathrm{SiO}_{2}$, up to a concentration of $10 \mathrm{~mol} \%$, do not affect the high temperature superconductivity of $\mathrm{YBa}_{2} \mathrm{Cu}_{3} \mathrm{O}_{7}$. Solid solubility of the above four oxides in $\mathrm{YBa}_{2} \mathrm{Cu}_{3} \mathrm{O}_{7}$ is limited (very small) as indicated by the $\mathrm{X}$-ray data where impurity phases are formed with an increase in the content of the oxide additive. $\mathrm{Bi}_{2} \mathrm{O}_{3}$ and $\mathrm{SiO}_{2}$ act as good sintering aids to $\mathrm{YBa}_{2} \mathrm{Cu}_{3} \mathrm{O}_{7}$ giving rise to larger grain size and better interconnectivity of the grains. The latter should aid in increasing the critical current density $\left(J_{c}\right)$ of $\mathrm{YBa}_{2} \mathrm{Cu}_{3} \mathrm{O}_{7}$ in bulk form.

\section{Acknowledgement}

Thanks are due to the Regional Sophisticated Instruments Centre and Ms Shanthi Devanathan, $\mathrm{Mr} \mathrm{N}$ Sivaramakrishnan and $\mathrm{Mr} \mathrm{T}$ Rajkumar for the SEM photographs; to the Central XRD Lab, Mr S Umapathy and Mr Varadachary for $\mathrm{X}$-ray studies and to the Department of Science and Technology, New Delhi, and the Programme Management Board on Superconductivity for the award of research grants.

\section{References}

Cava R J, Batlogg B, van Dover R B, Murphy D W, Sunshine S, Siegrist T, Remeika J P, Rietman E A, Zahurak K and Espinosa G P 1987 Phys. Rev. Lett. 581676

Chaudhari P, Koch R H, Leibowitz R B, McGuire T R and Gambino R J 1987 Phys, Rev. Lett. 582684

Chu C W, Hor P H, Meng R L, Gao L, Huang Z J and Wang Y Q 1987 Phys. Rev. Lett. 58405

Dhar S K, Paulose P L, Grover A K, Sampathkumaran E V and Nagarajan V 1987 J. Phys. F17 L105

Dou S X, Savvides N, Sun X Y, Bourdillon A J, Sorrel C C, Zhou J P and Easterling K E 1987 J. Phys. C20 L1003

Dunlap B D, Slaski M, Hinks D G, Soderholm L, Beno M A, Zhang K, Segre C U, Crabtree C W, Kwok W K, Malik S K, Schuller I K, Jorgensen J D and Sungaila Z 1987 J. Magn. \& Magn. Mater. 68 L139

Ellis A B 1987 J. Chem. Educ. 64836

Engler E M 1987 Chem. Tech. 17542 
Engler E M, Lee V Y, Nazzal A I, Beyers R B, Lim G, Grant P M, Parkin S S P, Ramirez M L, Vazquez J E and Savoy R J 1987 J. Am. Chem. Soc. 1092848

Ganguly P, Mohan Ram R A, Sreedhar K and Rao C N R 1987 Pramana-J. Phys. 28321

Hikami S, Hirai T and Kagoshima B 1987 Jpn. J. Appl. Phys. 26 L314

Hosoya S, Shamoto S-L, Onoda M and Sato M 1987 Jpn. J. Appl. Phys. 26 L325, L456

Janaki J 1985 Ph.D Thesis, IIT, Madras (unpublished)

Jarvinen R J O, Niemi K J, Mantyla T A, Heikkila E S and Vuorinen P T 1988 Physica C153-155 882

Jin S, Sherwood R C, van Dover R B, Tiefel T H and Johnson Jr. D W 1987a Appl. Phys. Lett. 51203

Jin S, Tiefel T H, Sherwood R C, Kammlott G W and Zahurak S M 1987b Appl. Phys. Lett. 51943

Kilcoyne S H and Cyiwnski P 1987 J Phys. D20 1327

Krishnan H, Subramanian C K, Sankaranarayanan V, Srinivasan R, Mary T A, Varadaraju U V and Subba Rao G V 1989 Phys. Rev. B. (in press)

Malik M K, Nair V D, Biswas A R, Raghavan R V, Chaddah P, Mishra P K, Ravikumar G and Dasannacharya B A 1988 Appl. Phys. Lett. 521525

Malik M K, Nair V D, Raghavan R V, Chaddah P, Mishra P K, Ravikumar G and Dasannacharya B A 1987 Pramana-J. Phys. 29 L321

Matsushita A, Hatano T, Matsumoto T, Aoki H, Asada Y, Nakamura K, Honda K, Oguchi T and Ogawa K 1987 Jpn. J. Appl. Phys. 26 L1953

Montgomery H C $1971^{\prime} J$. Appl. Phys. 422971

Nagarajan V, Paulose P L, Grover A K, Dhar S K and Sampathkumaran E V 1987 Jpn. J. Appl. Phys. 26 (Suppl. 3) 1063

Narasimha Rao C V, Agarwal S K, Jayaram B and Narlikar A V 1988 Pramana-J. Phys. 31 L323

Paulose P L, Nagarajan V, Grover A K, Dhar S K and Sampathkumaran E V 1987 J. Phys. F17 L91

Rao C N R (ed.) 1988 Chemistry of oxide superconductors (Oxford: Blackwell Sci. Publ--IUPAC) p. 1

Rao C N R and Ganguly P 1987 Jpn. J. Appl. Phys. 26 L882

Rao C N R, Ganguly P, Raychaudhuri A K, Mohan Ram R A and Sreedhar K 1987 Nature (London) 326856

Sleight A W, Gillson J L and Bierstedt P E 1975 Solid State Commun. 1727

Sharma R G, Reddy Y S, Jha S R and Dubey S S 1988a Pramana $-J$. Phys. 30 L81

Sharma R G, Reddy Y S, Jha S R, Kundra K D and Suri D K 1988b Pramana-J. Phys. 30 L75

Srinivasan R, Sankaranarayanan V, Raju N P, Natarajan S, Varadaraju U V and Subba Rao G V 1987 Pramana-J. Phys. 29 L225

Subba Rao G V, Varadaraju U V, Srinivasan R and Radhakrishnan T S 1987a Phase Transitions 10181

Subba Rao G V, Varadaraju U V, Thomas K A, Vijayashree R, Raju N P, Srinivasan R, De U, Janaki J and Radhakrishnan T S 1987b Jpn. J. Appl. Phys. 26 (Suppl. 3) 1077

Subba Rao G V, Varadaraju U V, Vijayashree R, Padmanabhan K, Balakrishnan R, Mary T A, Raju N P, Srinivasan R, De U, Janaki J and Radhakrishnan T S 1987c Physica B148 237

Takagi H, Uchida S, Sato M, Kishio K, Kitazawa K, Fueki K and Tanaka S 1987 Jpn. J. Appl. Phys. 26 (Suppl. 3) 1029

Tiefel J M, Sherwood R C, Kmmiott G W and Zahurak S M 1987 Appl. Phys. Lett. 51943

Umarji A M and Nanjundaswamy K S 1987 Pramana-J. Phys. 29 L611

Varadaraju U V, Natarajan S, Sampathkumar T S, Paranthaman M, Subba Rao G V, Raju N P and Srinivasan R 1987 Physica B148 417

Varadaraju U V, Subba Rao G V, Chandrasekaran K D, Baradarajan A, Krishnajah K, Mukesh Agarwala, Achutharaman V S, Venugopal P, Padmanabhan K A, Vaidyanathan L S and Rangarajan G 1989 Bull. Mater. Sci. 1263

Wu M K, Ashburn J R, Torng C J, Hor P H, Meng R L, Gao L, Huang Z J, Wang Y Q and Chu C W 1987 Phys. Rev. Lett. $\mathbf{5 6} 908$

Xiao G, Streitz F H, Gavrin A, Du Y W and Chien C L 1987 Phys. Rev. 358782 